Afiasi: Jurnal Kesehatan Masyarakat, Vol. 4, No. 3, Desember 2019:105-111 ISSN Print : 2442-5885

\title{
Hubungan Antara Peran Orang Tua dengan Pengetahuan Anak Usia Sekolah dalam Melakukan Pencegahan Kekerasan Seksual
}

\section{Correlation of Parent Role with Knowledge and Attitudes of School-aged Children in Preventing Sexual Abuse}

\section{Wulan Khairini $^{1}$, Abdurrahman Hamid ${ }^{2}$, Yecy Anggreny ${ }^{3}$}

\author{
Program Studi: S1 Ilmu Keperawatan STIKes Hang Tuah Pekanbaru \\ E-mail: wulankhairini.1994@gmail.com ${ }^{1}$
}

\section{ABSTRAK}

Anak usia sekolah (AUS) merupakan kelompok resiko mengalami kekerasan seksual, namun kekerasan seksual ini dapat dicegah. Salah satu cara pencegahannya adalah dengan meningkatkan peran orang tua sebagai pendidik. Penelitian ini bertujuan mengetahui hubungan antara peran orang tua dengan pengetahuan AUS dalam melakukan pencegahan kekerasan seksual. Desain penelitian yang digunakan adalah deskriptif korelasi dengan menggunakan pendekatan cross sectional. Penelitian ini dilakukan di SD Negeri 38 Pekanbaru pada bulan Mei tahun 2018 dengan sampel berjumlah 124 orang. Hasil analisa univariat diperoleh sebagian besar orang tua memiliki peran baik yaitu berjumlah 63 orang $(50,8 \%)$, dengan pengetahuan AUS baik berjumlah 78 (62,9\%). Hasil uji Chi-Square terdapat hubungan yang signifikan antara peran orang tua dengan pengetahuan AUS dengan nilai $p$-value $=0,026<0,05$. Diharapkan orang tua menjalankan peran sebagai pendidik dengan baik sehingga dapat meningkatkan pengetahuan dan sikap AUS dalam memperoleh pendidikan seks.

Kata kunci : Anak Usia Sekolah, Orang Tua, dan Kekerasan Seksual

\section{ABSTRACT}

School-age children are a risk group to experience sexual violence, but this sexual violence can be prevented. One way to prevent this is to increase the role of parents as educators. This study aims to determine the relationship between the role of parents and knowledge of school-age children in preventing sexual violence. The research design used was descriptive correlation using a cross sectional approach. This research was conducted at state elementary school 38 Pekanbaru in May 2018 with a sample of 124 people. The results of univariate analysis showed that most parents had a good role, amounting to 63 people (50.8\%), with a good knowledge of school-age children amounting to 78 (62.9\%). Chi-Square test results showed a significant relationship between the role of parents and knowledge of school-age children with $p$-value $=0.026<0.05$. It is expected that parents carry out the role of educators well so that they can improve AUS's knowledge and attitudes in obtaining sex education.

Keywords: School-Age Children, Parents, and Sexual

Violence

\section{Pendahuluan}

Anak usia sekolah adalah anak dengan kategori yang banyak mengalami perubahan baik mental maupun fisik. ${ }^{1}$ Anak sekolah menurut definisi WHO (World Health Organization) yaitu golongan anak yang berusia antara 7-15 tahun. ${ }^{2}$ Masalah yang terjadi pada masa anak usia sekolah menurut WHO diantaraya adalah kekerasan seksual terhadap anak dibawah umur yang merupakan suatu tindakan penganiayaan atau perlakuan salah pada anak. ${ }^{2}$ Kekerasan seksual yang dilakukan terhadap anak adalah bentuk dari pemaksaan atau ancaman seorang kepada anak dalam aktivitas seksual. Aktivitas seksual yang dimaksud seperti melihat, meraba, penetrasi 
(tekanan), pencabulan dan pemerkosaan. Korban kekerasan seksual pada anak bisa mengalami kerugian fisik, mengalami luka atau kekerasan psikologis, dan trauma emosional. Kerugian yang dialami korban kekerasan seksual tidak hanya didapat dari aspek legal saja, tetapi juga akan didapat dari aspek sosial dan kultural. ${ }^{3}$

Angka kasus kekerasan seksual pada anak meningkat setiap tahunnya. Salah satunya di Provinsi Riau khususnya kota Pekanbaru. Dari data Polisi daerah Riau sekitar 150 anak di bawah umur di Provinsi Riau menjadi korban kekerasan seksual dengan angka kejadian tertinggi terjadi di Pekanbaru dengan 98 kasus, dimana pelakunya didominasi oleh orang terdekat dari korban. Orang terdekat yang dimaksud diantaranya Polda Provinsi Riau seperti paman, tetangga, dan kerabat jauh yang tinggal satu rumah dengan mereka. Polda Provinsi Riau juga melaporkan bahwa pada tahun 2015 menerima 50 laporan kasus kekerasan seksual, dengan demikian dari tahun 2014-2015 tercatat ada sekitar $148 .^{4}$

Banyak cara yang dapat dilakukan untuk melindungi anak dari tindak kekerasan seksual tersebut. Salah satunya dengan memanfaatkan peran orang tua sebagai pendidik untuk mengontrol sejauh mana tingkat pengetahuan, sikap, dan keterampilan anak sekolah dasar dalam melakukan pencegahan kekerasan seksual. Dalam perannya orang tua dapat memberikan informasi tentang seks dan mengajari anak tentang pentingnya perlindungan diri untuk mencegah terjadinya kekerasan seksual, dengan memberikan pengetahuan yang tepat kepada anak sekolah dasar dalam melakukan pencegahan kekerasan seksual.

Berdasarkan fenomena tersebut maka peneliti ingin melihat "Bagaimana hubungan antara peran orang tua dengan pengetahuan anak usia sekolah dalam melakukan pencegahan kekerasan seksual ?’.

\section{Metode}

Jenis penelitian ini adalah Kuantitatif dengan desain deskriptif korelasi dengan menggunakan pendekatan cross sectional, yaitu suatu penelitian yang menekankan waktu pengukuran atau observasi data variabel independen dan dependen hanya satu kali pada satu waktu. ${ }^{5}$ Peneliti menelaah dan membuktikan ada tidaknya hubungan antar variabel. Variabel-variabel yang dihubungkan dengan penelitian ini adalah variabel independen yaitu peran orang tua (pendidik) dan variabel dependen yaitu pengetahuan AUS. $^{6}$ Lokasi penelitian dilaksanakan di Sekolah Dasar Negeri 38 Pekanbaru Provinsi Riau. Kegiatan penelitin ini telah dilakukan dari tanggal 18 April 2018 sampai dengan 7 Mei 2018.

Dalam penelitian ini peneliti menggunakan teknik simple random sampling yaitu pengambilan anggota sampel dan populasi dilakukan secara acak tanpa memperhatikan strata yang ada dalam populasi itu. ${ }^{6}$ Dalam penelitian ini peneliti memakai kriteria inklusi dan ekslusi, sehingga peneliti hanya mengambil responden sesuai dengan kriteria. Alat ukur yang digunakan dalam penelitian ini berupa lembar kuesioner tentang peran orang tua dan tingkat pengetahuan anak usia sekolah dalam melakukan pencegahan kekerasan seksual. Alat ukur peran orang tua dan tingkat pengetahuan anak usia sekolah dilakukan uji validitas dan reliabilitas. Menurut Notoatmodjo Analisa data yang digunakan peneliti dalam penelitian ini dengan menggunakan 2 analisa, yaitu : Analisa univariat bertujuan untuk menjelaskan atau mendeskripsikan karakteristik setiap variabel penelitian, dimana akan menggambarkan bagaimana komposisinya ditinjau dari beberapa segi sehingga dapat dianalisis karakteristik responden dan Analisa bivariat yang dilakukan untuk menguji hubungan antara variabel independent dengan variabel dependent. Peneliti menjaga kerahasiaan responden, baik informasi maupun masalah-masalah lainnya dan peneliti hanya akan melaporkan hasil penelitian berupa data karakteristik responden 
serta nilai dari setiap jawaban yang diberikan responden untuk setiap item pernyataan yang diajukan peneliti. ${ }^{6}$

\section{Hasil}

\section{Analisa Univariat}

Tabel 1 Distribusi Frekuensi Karakteritik Analisa Univariat

\begin{tabular}{|c|c|c|c|}
\hline No & Karakteristik & $\begin{array}{c}\text { Frekuensi } \\
\text { (n) }\end{array}$ & $(\%)$ \\
\hline 1 & Rerata usia AUS & 10,28 & - \\
\hline 2 & $\begin{array}{l}\text { Jenis kelamin AUS } \\
\text { - } \quad \text { Laki-laki } \\
\text { - } \quad \text { Perempuan }\end{array}$ & $\begin{array}{l}70 \\
54 \\
\end{array}$ & $\begin{array}{l}56,5 \% \\
43,5 \%\end{array}$ \\
\hline 3 & $\begin{array}{l}\text { Jenis kelamin orang } \\
\text { tua/wali } \\
\text { - Laki-laki } \\
\text { - } \quad \text { Perempuan }\end{array}$ & $\begin{array}{l}47 \\
77\end{array}$ & $\begin{array}{l}37,9 \% \\
62,1 \%\end{array}$ \\
\hline 4 & $\begin{array}{l}\text { Umur orang } \\
\text { tua/wali } \\
\text { - } \quad 30-45 \\
-\quad 45-59 \\
\text { - } \quad>60\end{array}$ & $\begin{array}{l}78 \\
40 \\
6\end{array}$ & $\begin{array}{l}62,9 \% \\
32,3 \% \\
4,8 \%\end{array}$ \\
\hline 5 & $\begin{array}{l}\text { Pendidikan terakhir } \\
\text { Ayah } \\
\text { - } \quad \text { SD } \\
\text { - } \text { SMP } \\
\text { - } \quad \text { SMA } \\
\text { - } \quad \text { PT } \\
\end{array}$ & $\begin{array}{l}3 \\
30 \\
36 \\
55\end{array}$ & $\begin{array}{l}2,4 \% \\
24,2 \% \\
29,0 \% \\
44,4 \%\end{array}$ \\
\hline 6 & $\begin{array}{l}\text { Pendidikan terakhir } \\
\text { Ibu } \\
\text { - } \quad \text { SD } \\
\text { - } \quad \text { SMP } \\
\text { - } \quad \text { SMA } \\
\text { - } \quad \text { PT } \\
\end{array}$ & $\begin{array}{l}24 \\
9 \\
43 \\
48\end{array}$ & $\begin{array}{l}19,4 \% \\
7,3 \% \\
34,7 \% \\
38,7 \%\end{array}$ \\
\hline 7 & $\begin{array}{l}\text { Tingkat } \\
\text { pengetahuan AUS } \\
\text { - Baik } \\
\text { - } \quad \text { Buruk } \\
\end{array}$ & $\begin{array}{l}78 \\
46\end{array}$ & $\begin{array}{l}62,9 \% \\
31,7 \%\end{array}$ \\
\hline 8 & $\begin{array}{l}\text { Peran orang } \\
\text { tua/wali } \\
\text { - } \quad \text { Baik } \\
\text { - } \quad \text { Buruk }\end{array}$ & $\begin{array}{l}63 \\
61\end{array}$ & $\begin{array}{l}50,8 \% \\
49,2 \%\end{array}$ \\
\hline
\end{tabular}

Berdasarkan tabel 1 diketahui bahwa dari 124 responden yang diteliti diperoleh rerata usia responden AUS adalah usia 10,28 tahun. Jenis kelamin responden AUS mayoritas adalah lakilaki sebanyak 70 orang dengan persentase $56,5 \%$. Jenis kelamin responden orang tua/wali mayoritas adalah perempuan sebanyak 77 orang dengan persentase $62,1 \%$. Umur responden orang tua/wali mayoritas adalah 30-45 sebanyak 78 orang dengan persentase $62,9 \%$. Pendidikan terakhir responden ayah mayoritas adalah perguruan tinggi sebanyak 55 orang dengan persentase $44,4 \%$. Pendidikan terakhir responden ibu mayoritas adalah perguruan tinggi sebanyak 48 orang dengan persentase $38,7 \%$. Tingkat pengetahuan AUS tentang kekerasan seksual mayoritas dengan kategori berpengetahuan baik, yaitu sebanyak 78 dengan persentase 62,9\%. Peran Orang Tua/Wali terhedap Pengetahuan AUS dalam melakukan pencegahan kekerasan seksual terhadap AUS di SDN 38 Pekanbaru mayoritas dengan kategori berperan baik, yaitu sebanyak 63 dengan persentase $50,8 \%$. 
Afiasi: Jurnal Kesehatan Masyarakat, Vol. 4, No. 3, Desember 2019:105-111 ISSN Print $\quad$ :2442-5885

Journal homepage: http://afiasi.unwir.ac.id

ISSN Online : 2622-3392

\section{Analisa Bivariat}

Tabel 2 Peran orang tua terhadap pengetahuan AUS tentang kekerasan seksual dalam upaya pencegahan kekerasan seksual di SDN 38 Pekanbaru

\begin{tabular}{|c|c|c|c|c|c|c|c|c|}
\hline \multirow{3}{*}{$\begin{array}{l}\text { Peran Orang } \\
\text { Tua/Wali }\end{array}$} & \multicolumn{6}{|c|}{ Pengetahuan AUS tentang Kekerasan Seksual } & \multirow{3}{*}{$\begin{array}{c}\text { OR } \\
95 \% \\
\text { CI }\end{array}$} & \multirow{3}{*}{$\begin{array}{c}P \\
\text { value }\end{array}$} \\
\hline & \multicolumn{2}{|c|}{ Baik } & \multicolumn{2}{|c|}{ Buruk } & \multicolumn{2}{|c|}{ Total } & & \\
\hline & $\mathrm{N}$ & $\%$ & $\mathrm{~N}$ & $\%$ & $\mathrm{~N}$ & $\%$ & & \\
\hline Baik & 31 & $49,2 \%$ & 32 & $50,8 \%$ & 63 & $50,8 \%$ & & \\
\hline Buruk & 42 & $68,9 \%$ & 19 & $31,1 \%$ & 61 & $49,2 \%$ & 1,4 & 0,026 \\
\hline Jumlah & 73 & $58,9 \%$ & 51 & $41,1 \%$ & 124 & $100 \%$ & & \\
\hline
\end{tabular}

Berdasarkan tabel 2 didapatkan hasil bahwa peran orang tua baik dengan pengetahuan AUS baik sebanyak 31 orang $(49,2 \%)$ dan peran orang tua baik pengetahuan AUS buruk sebanyak 32 orang (50,8\%). Sedangkan peran orang tua buruk dengan pengetahuan AUS baik sebanyak 42 orang $(68,9 \%)$ dan peran orang tua dengan pengetahuan AUS buruk sebanyak 19 orang $(31,1 \%)$.

Dari hasil uji statistis bivariat dengan menggunakan uji Chi Square yang sudah dilakukan diperoleh $p$ value 0,026. Dari hasil tersebut diketahui nilai $\mathrm{p}<\alpha(0,05)$, sehingga Ho ditolak. Maka dari itu dapat disimpulkan bahwa terdapat hubungan yang signifikan antara peran orang tua terhadap pengetahuan AUS tentang kekerasan seksual dalam upaya melakukan pencegahan kekerasan seksual. Dari hasil analisis diperoleh pula nilai $\mathrm{OR}=1,4$, artinya jika peran orang tua baik maka memiliki 1,4 kali peluang AUS memiliki pengetahuan yang baik.

\section{Pembahasan}

Hasil penelitian menunjukkan bahwa rerata umur AUS adalah 10,28 tahun. Periode ketika anak-anak dianggap mulai bertanggung jawab atas perilakunya sendiri dalam hubungan dengan orang tua mereka, teman sebaya, dan orang lainnya Hasil penelitian menunjukkan bahwa rerata AUS di SDN 38 Pekanbaru sedang berada pada tahap perkembangan kognitif individu di fase Operational Kongkrit, hal ini dijelaskan dari teori Seifert dan Haffung bahwa pada umur 7-11 tahun adalah fase dimana penggunaan logika yang memadai. Tahap ini telah memahami operasi logis dengan bantuan benda konkrit atau yang disebut dengan fase Operational Kongkrit. Sehingga ini juga memberikan pengaruh terhadap hasil penelitian yang dilakukan. ${ }^{1}$

Uji statistik analisa bivariat yang digunakan untuk melihat hubungan antara peran orang tua dengan pengetahuan AUS dalam melakukan pencegahan kekerasan seksual adalah uji Chi Square, dan diperoleh $p$ value 0,026. Dari hasil tersebut diketahui nilai $\mathrm{p}<\alpha(0,05)$, sehingga Ho ditolak. Maka dari itu dapat disimpulkan bahwa terdapat hubungan yang signifikan antara peran orang tua terhadap pengetahuan AUS tentang kekerasan seksual dalam upaya melakukan pencegahan kekerasan seksual. Setiati berpendapat bahwa, dalam mendidik AUS, sebagai orang tua terutama ibu memerlukan beberapa cara yang dianggap dapat membuat AUS merasa nyaman yaitu berbicara dengan baik dan lembut, ingin tahu kegiatan disekolah, senang saat bercerita, tidak ada batasan, membantu menghadapi masalah dan lain sebagainya. ${ }^{7}$ Peran orang tua yang baik adalah dengan memberikan pendidikan yang baik dan bermutu kepada anak-anaknya. Dalam hal mendidik anak orang tua harus menyesuaikan sesuai tahapan perkembangan anak-anaknya tidak boleh memaksakan kehendak dalam memberikan pendidikan. ${ }^{8}$

Berdasarkan hasil penelitian menunjukan bahwa tingkat pengetahuan AUS tentang kekerasan seksual pada 124 responden didapatkan mayoritas memiliki pengetahuan baik, yaitu sebanyak 78 dengan persentase 
62,9\%. Menurut Hidayat Pengetahuan adalah proses belajar dengan menggunakan pancaindra yang dilakukan seseorang terhadap objek tertentu untuk dapat menghasilkan pengetahuan dan keterampilan. Artinya dengan bantuan pancaindera tersebut individu akan sampai pada proses pembentukan kognitif, dimana pada akhirnya individu mampu mengadopsi suatu objek menjadi suatu tindakan atau perilaku. Dalam penelitian ini, pengetahuan responden yang baik tentang kekerasan seksual maka akan mempengaruhi AUS dalam melakukan pencegahan kekerasan seksual. Kerena dengan pengetahuan yang baik maka AUS bisa lebih mengetahui perilaku-perilaku apa saja yang dikategorikan dalam tindakan kekerasan seksual sehingga bisa menghindari tindakan kekerasan seksual tersebut. $^{9}$

Pada dasarnya pengetahuan merupakan salah satu bagian dari domain perilaku manusia. Dimana pengetahuan yang dimiliki oleh seseorang mempengaruhi perilakunya dalam bertindak, terutama dalam masalah kesehatan. Oleh kerena itu, pada individu yang mempunyai pengetahuan yang baik tentang masalah kesehatan maupun sosial diharapkan dapat meningkatkan tingkat kewaspadaan dan pencegahan agar terhindar dari tindak kejahatan kekerasan seksual terutama pada AUS.

Peneliti juga menemukan masih ada 16 anak $(12,9 \%)$ yang memiliki pengetahuan kurang tentang kekerasan seksual. Sehingga peneliti berharap bahwa orang tua bisa lebih memberikan perhatian yang khusus dalam memberikan pengetahuan seks pada anak-anak mereka khususnya pengetahuan tentang kekerasan seksual, hal ini dilakukan untuk mempermudah mereka dalam melakukan pencegahan kekerasan seksual. Pencegahan ini dilakukan juga untuk menghindari dampak yang ditimbulkan dari tindakan kekerasan seksual pada anak.

Peran orang tua yang paling berpengaruh dalam pertumbuhan dan perkembangan dimasa AUS adalah sebagai pendidik, karena para orang tualah yang paling mengerti benar akan sifat-sifat baik dan buruk anak-anaknya, apa saja yang mereka sukai dan apa saja yang mereka tidak sukai. Hal ini sejalan dengan teori Salwinsah yang menyatakan bahwa orang tua adalah yang pertama kali tahu bagaimana perubahan dan perkembangan karakter dan kepribadian anak-anaknya, hal-hal apa saja yang membuat anaknya malu dan hal-hal apa saja yang membuat anaknya takut. Para orang tualah yang nantinya akan menjadikan anakanak mereka seorang yang memiliki kepribadian baik ataukah buruk. Anak-anak pada masa usia sekolah lebih banyak membutuhkan perhatian dan kasih sayang dari orang tua mereka. ${ }^{10}$

Dari hasil analisis diperoleh pula nilai OR $=1,4$, artinya jika peran orang tua baik maka memiliki 1,4 kali peluang AUS memiliki pengetahuan yang baik. Peran yang dimaksud adalah peran orang tua sebagai pendidik. Karena anak-anak pada umumnya lebih mempercayai informasi yang diterima dari orang dewasa khususnya orang terdekat seperti orang tua, sebab jika dilihat dari segi kepercayaan, seseorang yang lebih dewasa akan mudah dipercaya dari orang yang belum tinggi kedewasaannya hal ini dikarenakan oleh faktor pengalaman dan kematangan jiwa. ${ }^{11}$ Anak-anak pada masa usia sekolah lebih banyak membutuhkan perhatian dan kasih sayang dari orang tua mereka. Anak usia sekolah juga lebih banyak menghabiskan waktu bersama orang tua sehingga sangat efektif bagi para orang tua untuk memberikan edukasi dan informasi yang tepat dan benar kepada mereka. ${ }^{12}$

Salah satu fungsi orang tua berdasarkan teori Effendy adalah asah. Asah merupakan fungsi orang tua untuk memenuhi kebutuhan pendidikan anak, sehingga siap menjadi manusia dewasa yang mandiri dalam mempersiapkan masa depannya. Fungsi ini diharapkan mampu membantu AUS untuk memenuhi semua bentuk pengetahuan intelektual mereka agar dapat menuju kebutuhan pemeliharaan dan perawatan anak agar kesehatannya selalu terpelihara, sehingga diharapkan menjadikan mereka anak-anak yang sehat baik fisik, mental, sosial dan spiritual. ${ }^{13}$ 
Baik maupun buruknya pengetahuan anak merupakan tanggung jawab orang tua, jika orang tua menjalankan peran sebagai pendidik dengan baik maka anak akan tumbuh dengan memiliki pengetahuan yang baik begitu pula sebaliknya jika orang tua menjalankan peran sebagai pendidik dengan buru maka anak akan tumbuh dengan memiliki pengetahuan yang buruk baik dalam pengetahuan umum, sosial maupun pengetahuan mereka tentang seks dan kekerasan seksual. Hal ini sejalan dengan teori Salwinsah yang menyatakan bahwa orang tua merupakan orang yang nantinya akan bertanggung jawab dalam menjadikan anakanak mereka seorang yang memiliki kepribadian baik ataukah buruk. ${ }^{10}$

Peneliti berpendapat bahwa ditemukan adanya hubungan antara peran orang tua dengan pengetahuan AUS tentang kekerasan seksual ini didasari oleh sebagian besar pengetahuan AUS yang baik dan juga peran orang tua yang baik pula. Penelitian ini juga menemukan ada AUS yang memiliki pengetahuan buruk tapi peran orang tua mereka baik dan sebaliknya ada AUS pengetahuan baik tapi peran orang tua nya yang buruk, hal ini bisa terjadi karena orang tua kurang memperaktekan ilmu yang mereka dapat dalam mendidik anak mereka dirumah. Adanya hubungan yang baik terhadap AUS dan orang tua membuat AUS merasa nyaman dan aman saat bercerita dengan orang tuanya, sehingga AUS akan terbuka dengan masalah-masalah mereka, terlebih lagi mengenai masalah tentang kekerasan seksual dan tentang awal pubertas mereka, dalam hal ini orang tua harus memberikan pengarahan dan pengetahuan yang tepat tentang hal tersebut. Sehingga anak akan terarah pengetahuannya menjadi lebih baik.

\section{Kesimpulan}

Berdasarkan uraian dari hasil penelitian diketahui bahwa terdapat hubungan antara peran orang tua dengan pengetahuan anak usia sekolah dalam melakukan pencegahan kekerasan seksual. Diketahui pula bahwa mayoritas responden AUS memiliki pengetahuan yang baik tentang kekerasan seksual. Dari penelitian ini juga peneliti menemukan bahwa sebagian besar responden orang tua / wali memiliki peran yang baik terhadap pengetahuan AUS dalam melakukan pencegahan kekerasan seksual.

\section{Referensi}

1. Wong, D. L., Hockenberry, M. E., Wilson, D., Winkelstein, M. L., \& Schwartz, P. 2008. Buku ajar keperawatan pediatrik (Agus Sutarna, Neti Juniarti \& H.Y. Kuncara, Penerjemah). (6 $6^{\text {th }}$ Ed., Vol 1). Jakarta : EGC.

2. World Health Organization (WHO). 2011. Preventing child maltreatment : a guide to taking action and generating evidence. World Health Organization and International Society for Prevention Of Child abuse and Neglect.

3. Salwinsah. 2018. Tugas-tugas perkembangan. Jakarta : Cindikia.

4. Noviana I. 2015. Kekerasan seksual terhadap anak: dampak dan penanganannya (Child sexual abuse: impact and hendling). Jurnal ilmiah. Di unduh pada 2018 dari : https://media.neliti.com/media/publications/ 52819-ID-kekerasan-seksual-terhadapanak-dampak-d.pdf .

5. Nursalam. 2011. Konsep dan penerapan metode penelitian ilmu keperawatan. Jakarta: Salemba Medika.

6. Paramastri, Supriyati, dan Priyanto. 2011. Early prevention toward sexual abuse on ch ildren. Jurnal ilmiah kesehatan. Vol.37. No.1. Di unduh pada 2018 dari: https://jurnal.ugm.ac.id/jpsi/article/viewFile /7688/5955.

7. Patricia. 2014. "Haruskah anak kita menjadi korban?" Newsletter Pulih, Volume 15 tahun 2010, hal. 4. Jakarta: Yayasan Pulih.

8. Sujarweni,V., W. 2014. Metodologi penelitian. Yogyakarta: Pustaka Baru Press.

9. Notoatmodjo, S. 2010. Metodologi penelitian kesehatan. Jakarta: Rineka Cipta. 
Afiasi: Jurnal Kesehatan Masyarakat, Vol. 4, No. 3, Desember 2019:105-111 ISSN Print : 2442-5885

Journal homepage: http://afiasi.unwir.ac.id

ISSN Online : 2622-3392

10. Badan Koordinasi Keluarga Berencana Nasional. 2011. Kekerasan seksual pada Anak. Jakarta : BKKBN.

11. Effendy., Ferry., dan Makhfudli. 2011. Keperawatan Kesehatan Komunitas-Teori dan Praktek dalam Keperawatan. Jakarta: Salemba Medika

12. Elder. 2009. Understanding Child Abuse and Neglect. Diterjemahkan oleh Timur Citra Sari dan Mareike Bangun. Jakarta: Gunung Mulia 